\title{
Making a timely diagnosis of pulmonary tuberculosis
}

\author{
Richard Long MD
}

\begin{abstract}
R Long. Making a timely diagnosis of pulmonary tuberculosis. Can Respir J 2015;22(6):317-321.

Making a timely diagnosis of adult-type pulmonary tuberculosis (TB) is critical to interrupting transmission and optimizing treatment outcomes. A hypothesis based on clinical experience is that a timely diagnosis may be made by addressing seven clinical rubrics: six related to history, one to the laboratory. Responses may be considered to be part of a clinical heuristic for making a timely diagnosis of pulmonary TB. The larger the number of affirmative responses, the more likely the diagnosis, although it is probable some questions carry more weight than others. The radiograph is key and may almost be considered to be confirmatory of the history. Collectively, the responses should prompt suspicion of pulmonary TB - submission of sputum for acid-fast bacilli smear and culture, and respiratory isolation.
\end{abstract}

Key Words: Diagnosis of pulmonary tuberculosis

$\mathrm{T}$ uberculosis (TB) is the quintessential public health disease. It is caused by Mycobacterium tuberculosis, a bacterium that co-opts a biological necessity of its human host - the act of breathing - to effect its own airborne transmission and survival. With few exceptions, transmission of the organism results from cases of pulmonary TB, defined here as TB that is culture positive and involves the lungs and conducting airways. Droplet nuclei, sometimes referred to as 'the quanta of contagion', are created when pulmonary TB patients make forceful expiratory efforts, such as coughing, sneezing, singing, playing wind instruments and even speaking (1). These droplets have an extremely slow settling rate $(\leq 0.5 \mathrm{~mm} / \mathrm{s})$, which permits their transport by air currents, duct systems and elevator shafts for significant distances from the source case. Only the droplet nuclei in the size range of $1 \mu \mathrm{m}$ to $5 \mu \mathrm{m}$ reach the terminal airspaces or alveoli of contacts; each is understood to contain only a few bacteria. In most instances, only one such droplet nucleus is responsible for establishing infection in the host (1). Just how many contacts become infected is largely dependent on the number of infectious droplet nuclei per volume of air (infectious particle density) and the length of time that the uninfected individual spends breathing that air.

For $>50$ years, the means have been at hand to eliminate TB; however, the disease remains very much extant especially in minority groups and the impoverished, wherever they may reside. If most TB disease in a community reflects recent/ongoing transmission, which is believed to be the case in many indigenous communities in Canada, the first priority of a TB control program is to prevent further transmission. If, on the other hand, most TB disease reflects reactivation of remotely acquired infection, as is believed to be the case in many foreign-born persons in Canada, the priority should shift to identification and treatment of people with latent TB infection (LTBI), notably those with risk factors for reactivation. Both interruption of transmission and prevention of disease are required for TB elimination. The present discussion focuses on the interrupting of transmission by identifying ways to make diagnosis timely. 'Timely' because the interruption need not be immediate or complete, only that the rate of transmission be held permanently below the level at which a given number of infection-spreading cases

\author{
Poser un diagnostic rapide de tuberculose \\ pulmonaire
}

Il est essentiel de diagnostiquer rapidement la tuberculose chez les adultes pour en interrompre la transmission et optimiser les résultats cliniques des traitements. D'après une hypothèse fondée sur l'expérience clinique, il est possible de poser un diagnostic rapide grâce à sept éléments cliniques, dont six liés aux antécédents et un aux résultats de laboratoire. On peut considérer les réponses comme des éléments de l'heuristique clinique pour le diagnostic rapide de TB pulmonaire. Plus le nombre de réponses affirmatives est élevé, plus le diagnostic est probable, même s'il se peut que certaines questions aient plus d'importance que d'autres. La radiographie est essentielle et peut presque être considérée comme une confirmation des antécédents. Collectivement, les réponses devraient susciter une présomption de TB pulmonaire et l'obtention d'expectorations pour le frottis et la culture de bacilles acido-alcoolo-résistants et l'isolation respiratoire.

succeed in establishing an equivalent number to continue the cycle (2). What follows is a brief review of the literature describing patient factors affecting TB transmission, although it is recognized that environmental (social and physical) and potentially pathogenic factors may also influence the likelihood of transmission, largely by affecting the number of infectious droplet nuclei per volume of air, and the number and proximity of susceptible contacts (1).

\section{PATIENT FACTORS AFFECTING TB TRANSMISSION Age \\ For a pulmonary $\mathrm{TB}$ patient to transmit to others, they must be able to generate an infectious aerosol. As a general rule, children $<10$ years of age and, especially, those $<5$ years of age, have few bacilli in their lungs and cannot generate such aerosols (1). Adolescents and adults, on the other hand, can and often do generate infectious aerosols.}

\begin{abstract}
Smear status
It is well established that patients with smear-positive pulmonary TB are approximately five times more infectious than patients with smearnegative pulmonary TB $(3,4)$. Moreover, the risk for disease after infection from a smear-positive case is greater by virtue of the higher probability of reinfection having occurred $(5,6)$. Years ago, in a series of elegant studies, RG Ferguson showed that during the first 12 to 24 months after the initial infection, each reinfection carries an equivalent risk for disease (5).

Disease phenotype

Pulmonary TB patients with cavitations on chest radiograph are more likely than those without cavitations to be infectious. Smear-positive pulmonary TB patients with typical adult-type pulmonary TB; that is, TB involving the upper lung zones with or without cavitations, but no discernible adenopathy, are more likely than those without typical adult-type pulmonary TB on chest radiograph to be infectious (7-11). Patients with laryngeal TB; that is, inflammation and ulceration of the vocal cords causing hoarseness, usually have far advanced pulmonary $\mathrm{TB}$ upstream from the larynx and are highly infectious.
\end{abstract}

Tuberculosis Program Evaluation and Research Unit, Department of Medicine, University of Alberta, Edmonton, Alberta

Correspondence and reprints: Dr Richard Long, Room 8334A, Aberhart Centre, 11402 University Avenue, Edmonton, Alberta T6G 2J3.

Telephone 780-407-1427, fax 780-407-1429, e-mail richard.long@ualberta.ca 


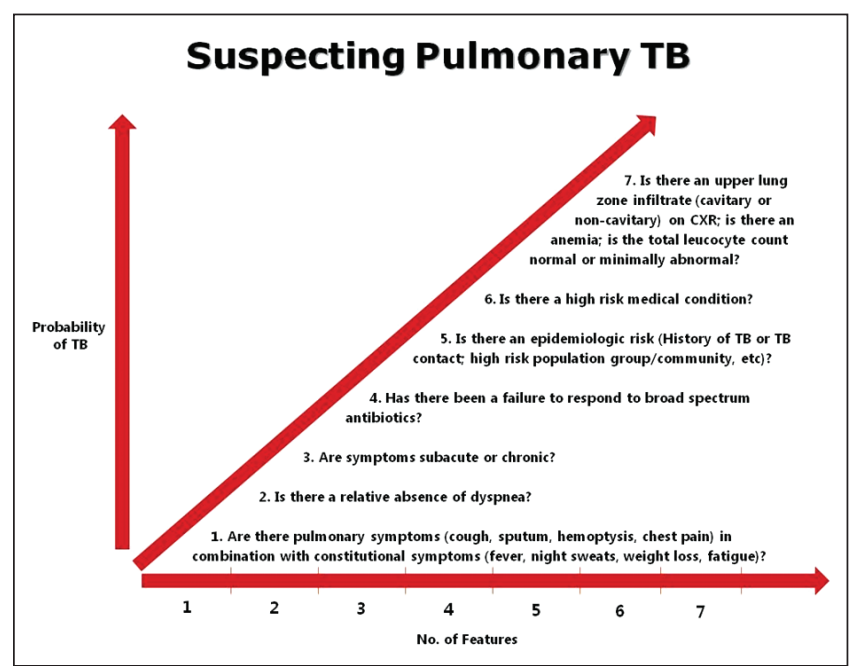

Figure 1) Seven questions that, collectively, determine the probability of pulmonary tuberculosis (TB). CXR Chest $x$-ray

\section{Symptomatology}

In general, normal breathing produces few infectious particles, a bout of coughing or $5 \mathrm{~min}$ of speaking in a normal tone produce many more, and a sneeze produces the most $(12,13)$. The likelihood that household contacts will be infected increases with the frequency of cough in the source case (14). Not all patients with smear-positive pulmonary $\mathrm{TB}$ are equally likely to transmit. When the aerial infectivity of the droplets from smear-positive patients was evaluated by artificially atomizing sputum and exposing guinea pigs to a standard dose, there was marked variability in the infectivity of aerosolized sputum (15-17). Some patients are 'super-spreaders' while others transmit very little $(16,17)$. This heterogeneity almost certainly relates to the physical and chemical properties of the sputum (rheology) and the effectiveness of the patient to aerosolize. Cough aerosol production is now known to predict transmission better than sputum smear microscopy or culture (18). The longer the duration of symptoms in the source case the greater the risk of transmission (19).

\section{Treatment}

Effective treatment; that is, treatment that is appropriate to the $M$ tuberculosis drug susceptibility test results, rapidly reduces the cough frequency and sputum bacillary counts. For practical purposes, patients on effective treatment are considered to be noninfectious in a matter of days to weeks (1).

\section{MAKING A TIMELY DIAGNOSIS OF PULMONARY TB}

Interrupting transmission and optimizing treatment outcomes of pulmonary TB depend on a timely diagnosis. A hypothesis based on clinical experience is that a timely diagnosis may be made by addressing seven clinical rubrics: six related to history, one to the laboratory (Figure 1). Responses may be considered part of a clinical heuristic for making a timely diagnosis of pulmonary TB. The larger the number of affirmative responses the more likely the diagnosis, although it is probable some questions carry more weight than others. The radiograph is key (see below) and may almost be considered confirmatory to the history. Taken together, the responses should prompt suspicion of pulmonary TB - submission of sputum or other airway secretions for acidfast bacilli smear and culture, and respiratory isolation.

1. Are there pulmonary symptoms (cough, sputum, hemoptysis, chest pain) in combination with constitutional symptoms (fever, night sweats, weight loss, fatigue)? Although some patients with pulmonary TB may be asymptomatic, especially those with minimal disease, most cases, especially those with moderate or faradvanced disease have one or more symptom complex, either

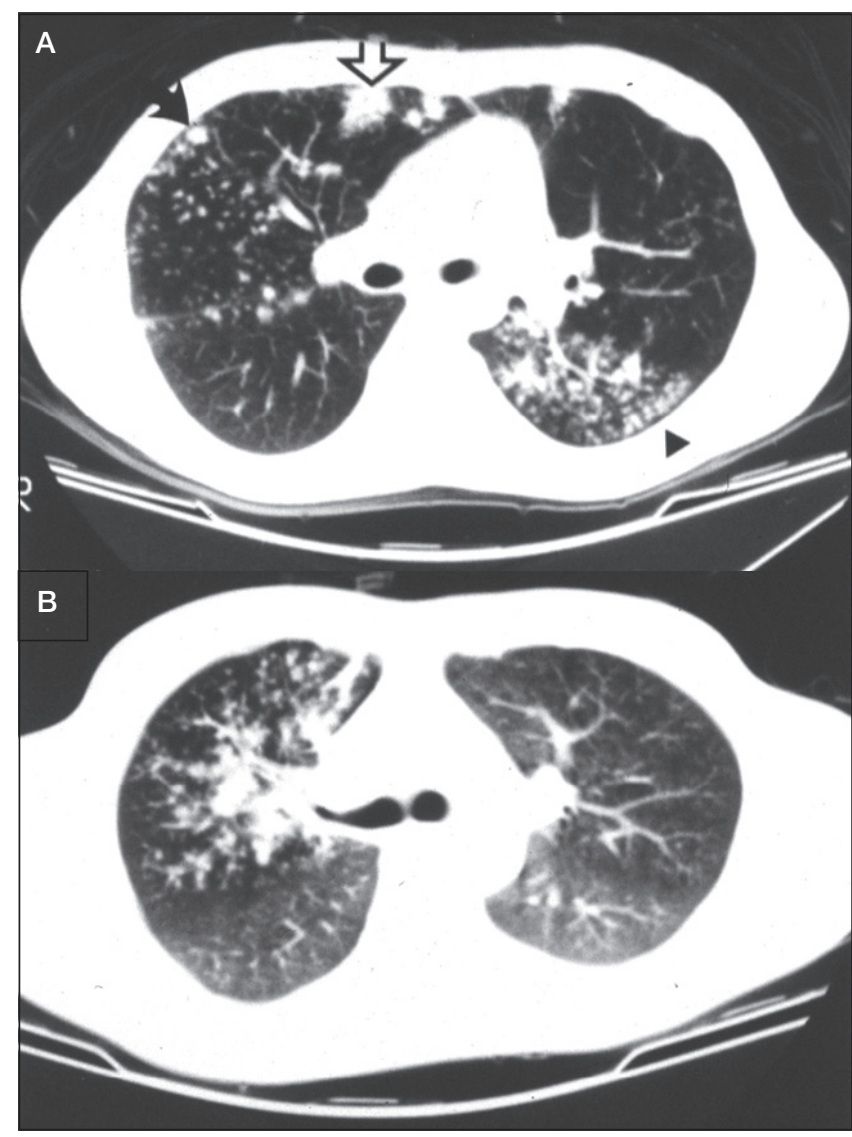

Figure 2) A A computed tomographic scan obtained at the level of the main bronchi in a 23-year-old man with extensive bronchogenic spread of tuberculosis (TB). Centrilobular nodules, 'tree-in-bud' (arrowhead), 'acinar' nodule (solid arrow) and lobular consolidation with air bronchogram (open arrow) are apparent. B A computed tomographic scan obtained at the level of the carina in a 37-year-old male patient with bronchogenic spread of TB involving the entire right upper lobe

pulmonary, constitutional or both. Pulmonary $\mathrm{TB}$ is an endobronchial disease and, therefore, likely to generate cough and sputum (Figure 2) (20). Tubercle bacilli, as do other bacteria such as Gram-negative bacilli, staphylococci and anaerobes, produce lung necrosis and hemoptysis. Bronchiectasis is a recognized complication of pulmonary TB (20). Patients with moderate to far-advanced pulmonary TB often have constitutional symptoms in addition to pulmonary symptoms. Cachectin or tumour necrosis factor, a cytokine that is released during the inflammatory response to $\mathrm{TB}$, is in large measure responsible for the constitutional symptoms (21). Alone, the presence of 'any TB symptom' is a sensitive but nonspecific indicator of pulmonary TB (22).

2. Is there a relative absence of dyspnea? Physiological data are consistent with the concept that pulmonary TB is an endobronchial disease that causes parallel reductions in ventilation and perfusion (Figures 3 and 4) (20). This concurrent involvement of both airways and contiguous pulmonary blood supply is believed to explain why, despite extensive lung disease, these patients experience minimal respiratory limitation. Functional impairment, if present, is in proportion to the number of diseased segments and cavitary volume (20). Exceptions to this general rule include pulmonary TB complicated by pleural effusion, miliary dissemination, pneumothorax, hemorrhage, thromboembolic disease or pre-existing lung disease. Another includes the rare syndrome of acute tuberculous pneumonia, where a large volume of liquid caseum suddenly enters a lobar or main bronchus in a sensitized host. In this scenario, hypoxemia results from 


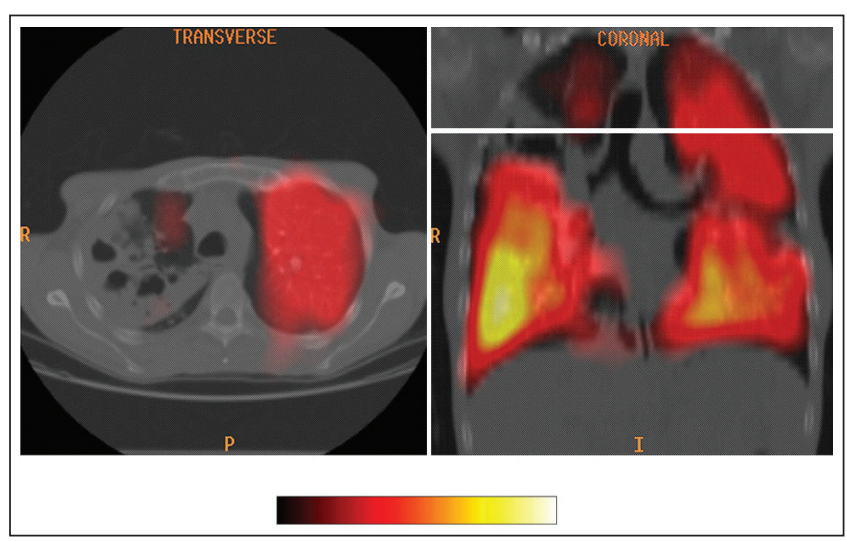

Figure 3) A colour ventilation scan superimposed on a computed tomographic image of the thorax in a patient with smear-positive right upper lobe cavitary pulmonary tuberculosis

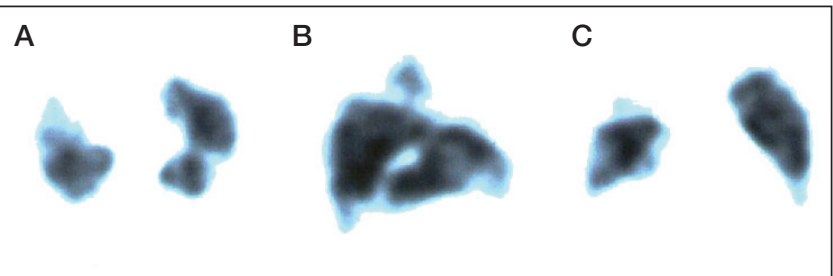

Figure 4) Perfusion images (A, transverse; $\mathrm{B}$, lateral; $\mathrm{C}$, frontal) in the same patient as Figure $2 \mathrm{~B}$ above, demonstrating a prominent perfusion defect in the right upper lobe

airspace consolidation due to flooding of terminal lung units and hypersensitivity to tuberculoprotein without a compensatory reduction in perfusion (23-26). Interruption of perfusion in parallel with ventilation may serve the pathogen; limitation of physiological impairment extending the life of the host within the community, thereby creating an opportunity for further transmission (20).

3. Are the symptoms subacute or chronic? M tuberculosis is a slow growing pathogen and the disease it causes is often insidious in onset. In contrast to community-acquired pneumonia, which tends to be acute, with symptoms measured in days, pulmonary TB patients have usually been symptomatic for weeks, months or sometimes even years before presentation.

4. Has there been a failure to respond to broad-spectrum antibiotics, fluoroquinolones excepted? Because most pulmonary TB patients have been subacutely or chronically ill, it is not uncommon for them to have been seen by a physician and prescribed one or more courses of broad-spectrum antibiotics, without appreciable benefit, with the exception of the fluoroquinolones. Compared with other broadspectrum antibiotics such as beta lactams and macrolides used to treat community-acquired pneumonia that have little or no activity against TB, fluoroquinolones, especially the third- and fourthgeneration fluoroquinolones, have excellent bactericidal activity against $M$ tuberculosis. Their administration as monotherapy can cause clinical and radiographic improvement while inducing fluoroquinolone resistance (27-29).

5. Is there one or more epidemiological risk factor? Although it is axiomatic that infection must precede disease, exposure history and risk for infection, especially recent infection that carries the greatest risk of disease, can of course vary (30). Summarized below are questions that relate to the epidemiological risk for infection and disease. Does the patient have a history of TB or overt TB contact? Collateral history may be available from the provincial or territorial TB registries. If there is a history of overt TB contact, was the contact recent, close or household; was the source case smear positive? If diagnosed with active TB or LTBI in the past,

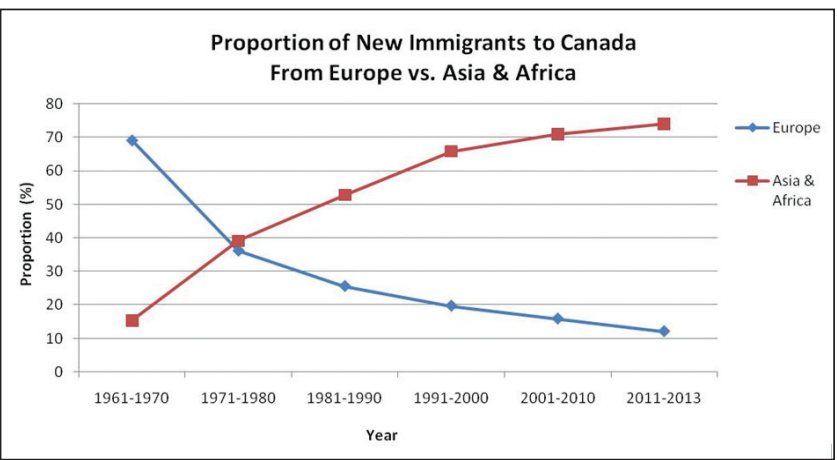

Figure 5) Proportion of new immigrants to Canada from Europe and Asial Africa according to time period. Source: Citizenship and Immigration Canada. Canadian Statistics: Immigrant population. Increasingly over the past 60 years immigrants to Canada have been arriving from high incidence countries

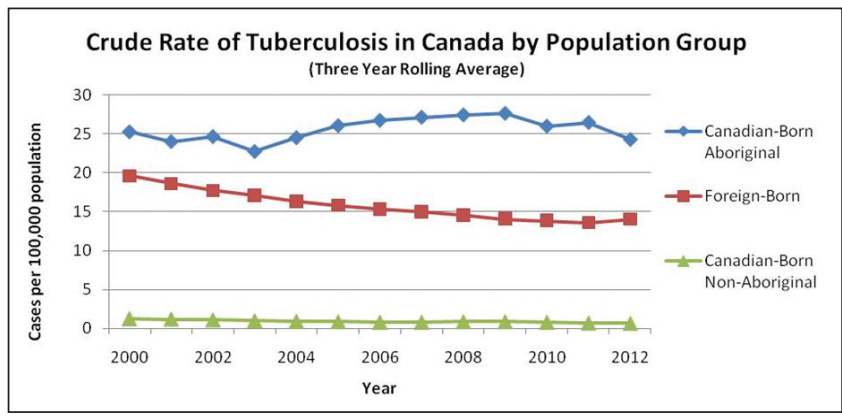

Figure 6) Crude rates of tuberculosis in Canada (1999 to 2013) as reported by the Public Health Agency of Canada

was their treatment considered to be adequate? Is there a travel history to a high-incidence country, an occupational history, recent homelessness or incarceration, where nonovert exposure may have occurred? Other questions relating to epidemiological risk include the population group of the patient; for years now TB in Canada has been concentrated in two population groups: foreign-born persons and indigenous peoples (Figures 5 and 6). If foreign-born, are they a refugee? Compared with landed immigrants, refugees have approximately twice the incidence of TB (31). Are they an immigrant to Canada from a high-incidence country and, if so, are they recently arrived? The risk of TB in Canada is directly related to the incidence of TB in their country of birth and highest in recent arrivals (32). If Canadian-born, are they First Nations, Métis or Inuit and living in a high-incidence community? In the prairie provinces, First Nations and Métis communities are heterogeneous with respect to the likelihood of pulmonary TB (33).

6. Is there a predisposing medical condition? Risk factors for the development of active TB among persons with a positive tuberculin skin test; that is, those who are presumed to be infected with $M$ tuberculosis, are well known. In the Canadian Tuberculosis Standards, $7^{\text {th }}$ Edition, they have been grouped according to degree of risk as high, moderate, slight, low and very low (Table 1) (34). Most high or moderate risk factors are medical conditions, such as HIV, dialysis-dependent renal failure and diabetes, or use of drugs such as systemic corticosteroids, cancer chemotherapeutic agents, tumour necrosis factor inhibitors, or antirejection medications in transplant recipients, that compromise cellular immunological responses to TB. Other risk factors include recent infection and evidence of old healed TB on chest radiograph. The presence of one or more of these risk factors, especially one or more 'high' or 'moderate' risk factors, in a patient with symptoms and an epidemiological risk for TB can substantially increase the probability of their presenting complaints being tuberculosis related. 
TABLE 1

Risk factors for the development of active tuberculosis (TB) among individuals with a positive tuberculin skin test (TST) (presumed infected with Mycobacterium tuberculosis)

\begin{tabular}{lc}
\hline Risk factor & $\begin{array}{c}\text { Estimated risk } \\
\text { for TB* }\end{array}$ \\
\hline High risk & $110-170$ \\
AIDS & $50-110$ \\
HIV & $20-74$ \\
Transplantation (related to immune-suppressant therapy) & 30 \\
Silicosis & $7-50$ \\
Chronic renal failure requiring hemodialysis & 11.6 \\
Carcinoma of head and neck & 15.0 \\
Recent TB infection ( $\leq 2$ years) & $6-19$ \\
Abnormal chest x-ray - fibronodular disease & \\
Moderate risk & $1.5-5.8$ \\
Tumour necrosis factor alpha inhibitors & $2-3.6$ \\
Diabetes mellitus (all types) & 4.9 \\
Treatment with glucocorticoids ( $\geq 15$ mg/day prednisone) & $2.2-5$ \\
Young age when infected (0-4 years) & \\
Slightly increased risk & $3-4$ \\
Heavy alcohol consumption ( $\geq 3$ drinks/day) & $2-3$ \\
Underweight (<90\% ideal body weight; for most people, \\
$\quad$ this is a body mass index $\leq 20$ kg/m²) & $1.8-3.5$ \\
Cigarette smoker (1 pack/day) & 2 \\
Abnormal chest x-ray - granuloma & \\
Low risk & \\
Person with positive TST, no known risk factor, & \\
\hline Person with positive two-step TST (booster), no other & \\
\hline
\end{tabular}

${ }^{*}$ Relative to people with no known risk factor. Adapted from Can Respir $J$ 2013; 20 (SA): 45A

7. Is there an anemia; is the total leukocyte count normal or minimally abnormal; is there an upper lung zone infiltrate, cavitary or non-cavitary, on chest radiograph? These very basic laboratory investigations are usually all that is necessary after the history to prompt the physician to order sputum or other airway secretions for acid-fast bacilli smear and culture. The majority of patients with moderate to advanced disease are anemic, usually a reflection of chronic infection or micronutrient depletion related to malnutrition, which can be both a cause and effect of TB (35). The majority also have a normal to minimally abnormal total leukocyte count. Alone, both the hemoglobin and the total leukocyte count lack specificity. The plain chest radiograph, an accessible, inexpensive and safe investigation, is enormously helpful (Figure 7). Four features strongly suggest TB, especially when taken together with the above historical information: cavitation; distribution - adult-type pulmonary TB usually involves the apical and posterior segments of the upper lobes or the superior segments of the lower lobes; volume loss - the lung lesions of TB are polymorphic; each is on its own timetable; those that are more advanced will generate a fibrotic response (36); and poorly defined nodular opacities - the only feature of endobronchial disease that is apparent on plain chest radiograph.

\section{FUTURE CONSIDERATIONS}

Although attributing importance to the above constellation of questions in the diagnosis of pulmonary TB is unlikely to incite much of a polemic dialogue among those in TB control, the actual determination of probability in patients suspected of having disease, or the reliable

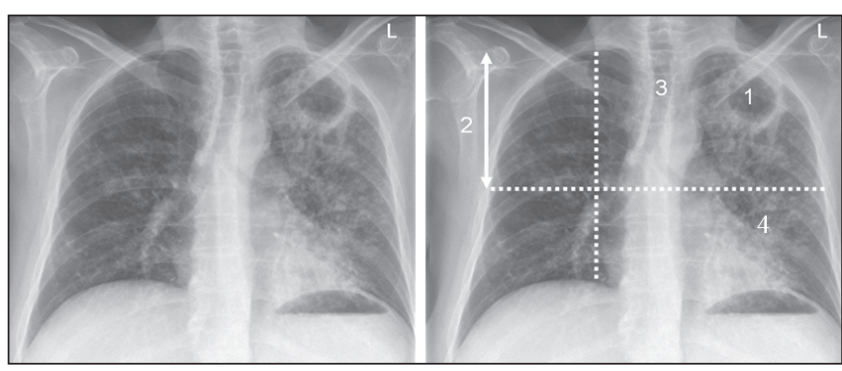

Figure 7) A posterior-anterior chest radiographic image in a patient with smear-positive cavitary pulmonary TB showing the four cardinal features of adult-type pulmonary TB.

connection of the responses to the disease, is another matter. In theory, suspicion and/or probability of pulmonary TB should increase progressively from those suspected of but not having the disease, to those with smear-negative disease, to those with smear-positive disease. Interest in this goes beyond the patient who is referred with suspected active disease and relates to the possibility that the aforementioned probability cascade might proceed in reverse; that is, from the chest radiograph to the history, even if TB was not suspected. In a population-based study in Canada, $70 \%$ of smear-positive culture-positive pulmonary TB cases had typical adult-type pulmonary TB on chest radiograph and, compared with cases without typical features, were more likely to have high bacillary burdens, cavitations and transmission events (11). Were it possible to automate the detection of typical adult-type pulmonary TB on digital films using computer-aided detection, quite independently of the ordering physician or radiologist considering TB, software could compute a probability based on the radiographic findings and historical information, provided the latter is available electronically. Some preliminary work in this regard has been undertaken $(37,38)$. If appropriately prompted, physicians and public health might pursue a yet more timely diagnosis.

DISCLAIMER: Presented at the American College of Chest Physicians/ Canadian Thoracic Society Meeting in Austin, Texas, October 27, 2014

ACKNOWLEDGEMENT: The author thanks the staff and students of the TB Program Evaluation and Research Unit at the University of Alberta and Dr Vivek Dhawan for their assistance in preparing the manuscript.

\section{REFERENCES}

1. Long R, Schwartzman K. Pathogenesis and transmission of tuberculosis. In: Menzies D, ed. The Canadian Tuberculosis Standards, 7th Edition. Can Respir J 2013;20(Suppl A):9A-15A.

2. Frost WH. How much control of tuberculosis? Am J Public Health and the Nation's Health 1937;27:759-66.

3. Behr MA, Warren SA, Salamon H, et al. Transmission of Mycobacterium tuberculosis from patients smear-negative for acid-fast bacilli. Lancet 1999;353:444-9.

4. Hernandez-Garduno E, Cook V, Kunimoto D, et al. Transmission of tuberculosis from smear-negative patients: A molecular epidemiologic study. Thorax 2004;59:286-90.

5. Ferguson RG. Studies in Tuberculosis. Toronto: University of Toronto Press, 1955.

6. Gryzbowski S, Barnett GD, Styblo K. Contacts of cases of active pulmonary tuberculosis. Report \#3 of TSRU. Bull Int Union Tuberc 1975;50:90-106.

7. Catanzaro A. Nosocomial tuberculosis. Am Rev Respir Dis 1982;125:559-62.

8. Bailey WC, Gerald LB, Kimmerling ME, et al. Predictive model to identify positive tuberculosis skin test results during contact investigations. JAMA 2002;287:996-1002.

9. Madhi F, Fuhrman C, Monnet I, et al. Transmission of tuberculosis from adults to children in a Paris suburb. Pediatr Pulmonol 2002;34:159-63. 
10. Long R, Maycher B, Scalcini M, Manfreda J. The chest roentgenogram in pulmonary tuberculosis patients seropositive for human immunodeficiency virus type 1. Chest 1991;99:123-27.

11. Lau A, Barrie J, Winters C, et al. The public health consequences of smear positive pulmonary tuberculosis in patients with typical versus atypical chest radiographs. International Union Against Tuberculosis and Lung Disease. North American Regional Meeting. Vancouver, February 24 to 26, 2011.

12. Louden RG, Roberts RM. Droplet expulsion from the respiratory tract. Am Rev Respir Dis 1967;95:435-42.

13. Louden RG, Roberts RM. Singing and the dissemination of tuberculosis. Am Rev Respir Dis 1968;98:297-300.

14. Louden RG, Romans WE. Cough frequency and infectivity in patients with pulmonary tuberculosis. Am Rev Respir Dis 1969;99:109-11.

15. Riley RL, Mills CC, Nyka W, et al. Aerial dissemination of pulmonary tuberculosis: A two year study of contagion in a tuberculosis ward. Am J Hyg 1959;70:185-96.

16. Sultan L, Nyka W, Mills C, et al. Tuberculosis disseminators: A study of the variability of aerial infectivity of tuberculosis patients. Am Rev Respir Dis 1960;82:358-69.

17. Riley RL, Mills CC, O'Grady F, et al. Infectiousness of air from a tuberculosis ward - ultraviolet irradiation of infected air: Comparative infectiousness of different patients. Am Rev Respir Dis 1962;85:511-25.

18. Jones-López EC, Namugga O, Mumbowa F, et al. Cough aerosols of Mycobacterium tuberculosis predict new infection: A household contact study. Am J Respir Crit Care Med 2013;187:1007-15.

19. Lohmann EM, Koster BF, le Cassie S, et al. Grading of positive sputum smear and the risk of Mycobacterium tuberculosis transmission. Int J Tuberc Lung Dis 2012;16:1477-84.

20. Long R, Maycher B, Dhar A, Manfreda J, Hershfield E, Anthonisen N. Pulmonary tuberculosis treated with directly observed therapy. Chest 1998;113:933-43.

21. Tracey KJ, Cerami A. Metabolic responses to cachectin/TNF. A brief review. Ann N Y Acad Sci 1990;587:325-31.

22. van't Hoog AH, Meme HK, Laserson KF, et al. Screening strategies for tuberculosis prevalence surveys: The value of chest radiography and symptoms. PLoS One 2012;7:e38691.

23. Rich AR. The Pathogenesis of Tuberculosis, 2nd edn. Springfield: Charles C Thomas, 1951.

24. Septimus EJ, Awe RJ, Greenberg SD, et al. Acute tuberculous pneumonia. Chest 1977;71:774-5.
25. Calix AA, Ziskind MM, Leonard AJ, et al. Acute tuberculous pneumonia in the negro. Am Rev Tuberc 1953;68:382-92.

26. Schwartz WS, Moyer RE. The management of massive tuberculous pneumonia. Am Rev Tuberc 1951;64:41-9.

27. Dooley KE, Golub J, Goes FS, Mers WG, Sterling TR. Empiric treatment of community-acquired pneumonia with fluoroquinolones, and delays in the treatment of tuberculosis. Clin Inf Dis 2002;34:1607-12.

28. Wang J-Y, Hsueh P-R, Jan I-S, et al. Empiric treatment with a fluoroquinolone delays the treatment for tuberculosis and is associated with a poor prognosis in endemic areas. Thorax 2006;61:903-8.

29. Long R, Chong H, Hoeppner V, et al. Empirical treatment of community-acquired pneumonia and the development of fluoroquinolone-resistant tuberculosis. Clin Inf Dis 2009;48:1354-60.

30. Ferebee SH. Controlled chemoprophylaxis trials in tuberculosis. A general review. Adv Tuberc Res 1970;17:28-106.

31. Greenaway C, Sandoe A, Vissandjee B, et al. Tuberculosis: Evidence review for newly arriving immigrants and refugees. CMAJ 2011;183:E939-E951.

32. Langlois-Klassen D, Wooldrage KM, Manfreda J, et al. Piecing the puzzle together: Foreign-born tuberculosis in an immigrant-receiving country. Eur Respir J 2011;38:895-902.

33. Long R, Hoeppner V, Orr P, et al. Marked disparity in the epidemiology of tuberculosis among Aboriginal peoples on the Canadian Prairies: The challenges and opportunities. Can Respir J 2013;20:223-30.

34. Menzies D, Alvarez GG, Khan K. Treatment of latent tuberculosis infection. In: Menzies D, ed. The Canadian Tuberculous Standards, 7th Edition. Can Respir J 2013;20(SA):44A-53A.

35. Oyer RA, Schlossberg D. Hematologic complications of tuberculosis. In: Schlossberg D, ed. Tuberculosis and Nontuberculous Mycobacterial Infections, 6th edn. Washington, DC: ASM Press, 2011:448-55.

36. Canetti G. The Tubercle Bacillus in the Pulmonary Lesion of Man. New York: Springer Publishing Company, Inc, 1955.

37. Xu T, Cheng I, Long R, Mandal M. Novel coarse-to-fine dual scale technique for tuberculosis cavity detection in chest radiographs. EURASIP Journal on Image and Video Processing. 2013, 2013:3. $<$ http://jivp.eurasipjournals.com/content/2013/1/3> (Accessed August 16, 2015).

38. Xu T, Cheng I, Long R, Mandal M. Computer-aided detection of acinar shadows in chest radiographs. ICTACT J Image Video Processing 2013;3:593-604. 


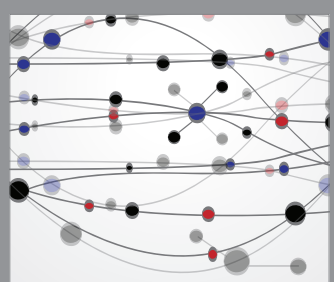

The Scientific World Journal
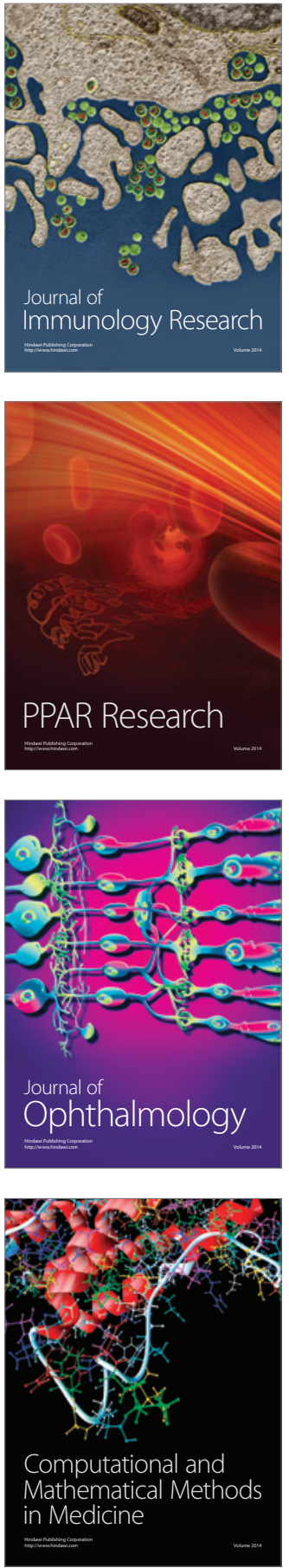

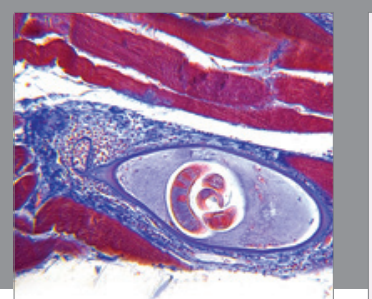

Gastroenterology Research and Practice

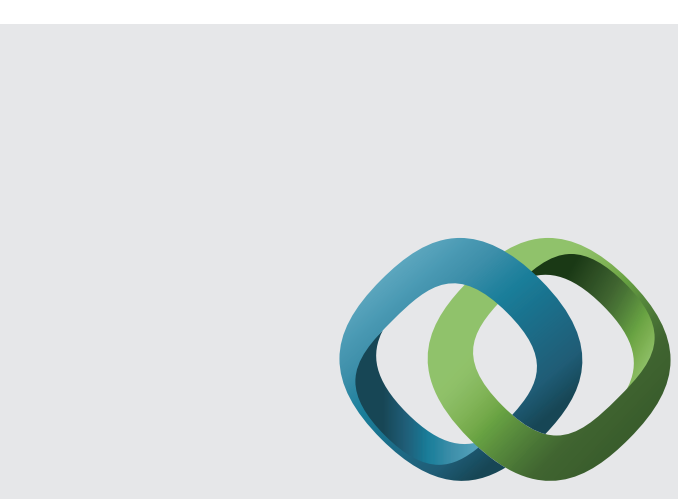

\section{Hindawi}

Submit your manuscripts at

http://www.hindawi.com
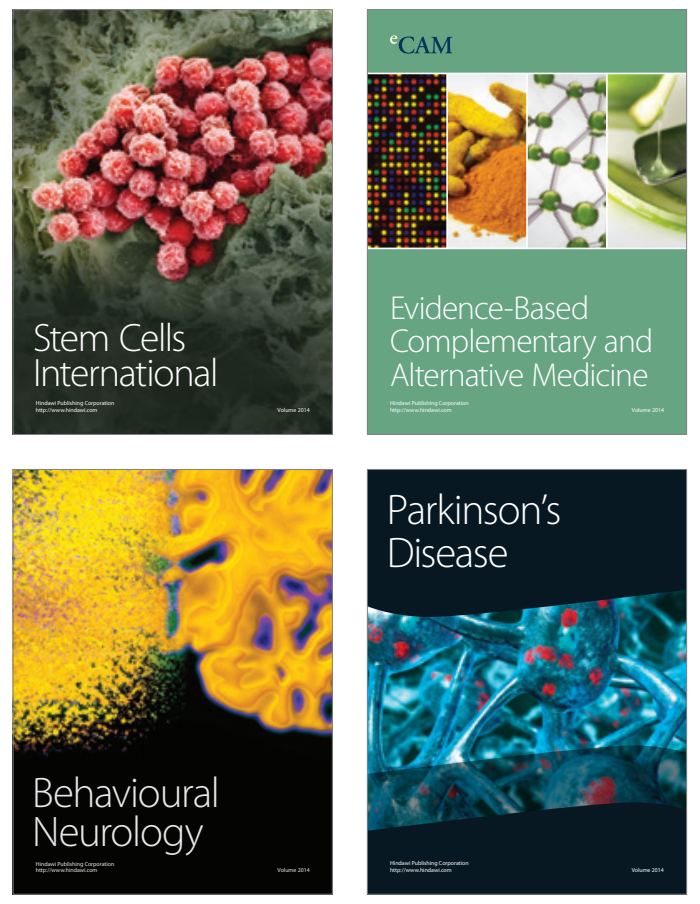
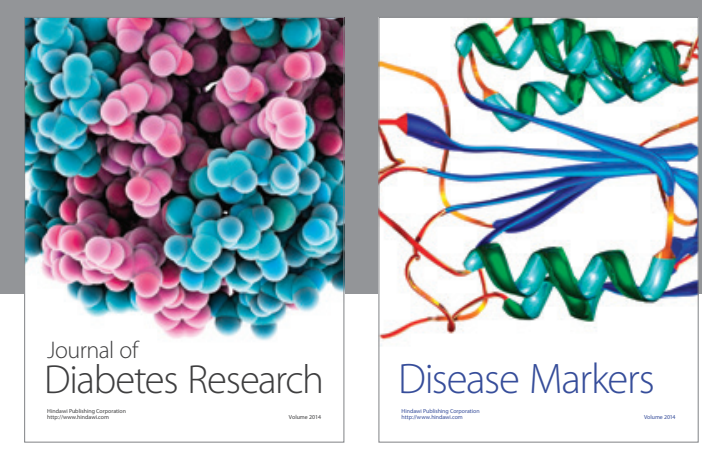

Disease Markers
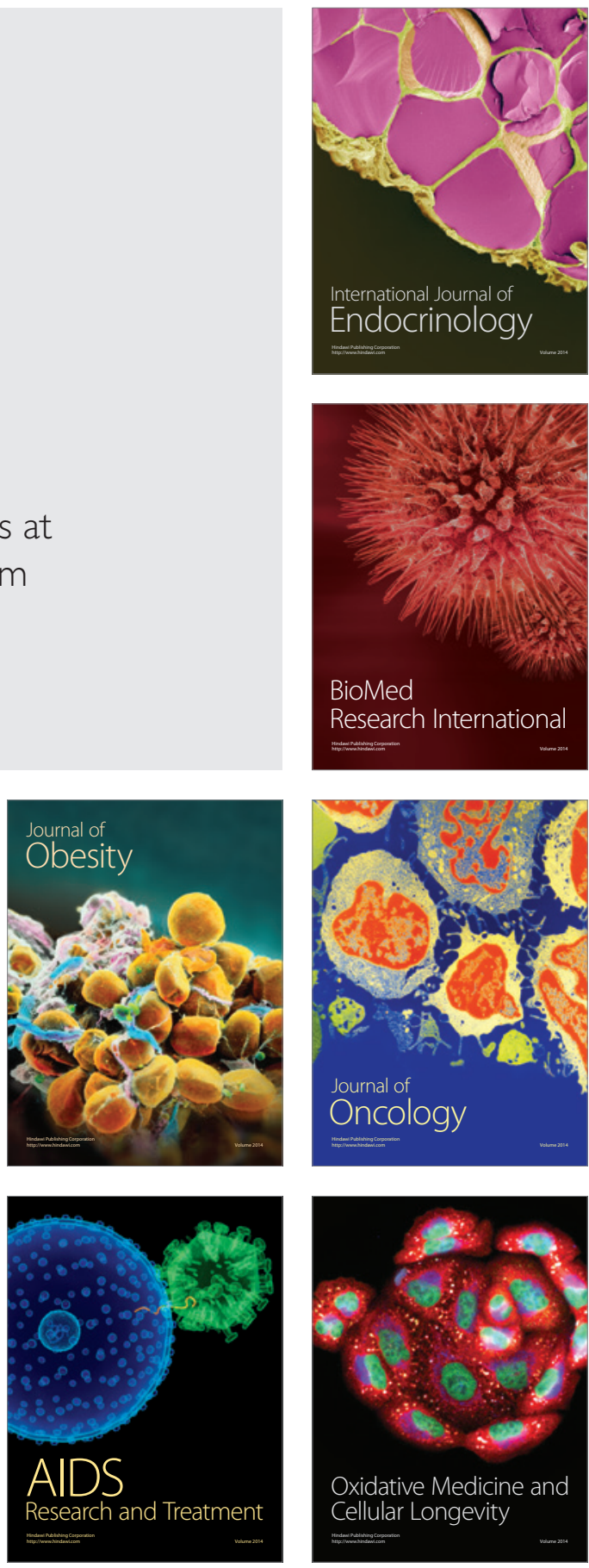